Comment

\title{
On the Pathogenesis of Crohn's Disease
}

Tommy Sundqvist ${ }^{1}$, Lars Stenhammar ${ }^{2,}{ }^{*}$, Bo Tjellström ${ }^{2,3}$, Karl-Eric Magnusson ${ }^{1}$, Tore Midtvedt ${ }^{3}$, Elisabeth Norin ${ }^{3}$, Lotta Högberg ${ }^{2}$

1. Division of Microbiology, Infection and Inflammation, Department of Biomedicine and Clinical Sciences, Linköping University, Linköping, Sweden; E-Mails: tommy.e.sundqvist@gmail.com; karl-eric.magnusson@liu.se

2. Department of Paediatrics and Department of Clinical and Experimental Medicine, Linköping University, Norköping, Sweden; E-Mails: larsstenhammar@yahoo.com; bo.tjellstrom@gmail.com; lotta.hogberg@regionostergotland.se

3. Department of Microbiology, Tumor and Cell Biology, Karolinska Institutet, Stockholm, Sweden; E-Mails: tore.midtvedt@ki.se; elisabeth.norin@ki.se

* Correspondence: Lars Stenhammar; E-Mail: larsstenhammar@yahoo.com

Academic Editor: Tony C. K. Tham

OBM Hepatology and Gastroenterology

2020 , volume 4, issue 1

doi:10.21926/obm.hg.2001043
Received: February 07, 2020

Accepted: March 03, 2020

Published: March 09, 2020

\section{Keywords}

Crohn's disease; inflammatory bowel disease; pathogenesis

To the Editor,

Van Kruiningen has recently suggested that the obstruction of the lymphatic vasculature is the fundamental mechanism in the pathogenesis of Crohn's disease (CD). [1, 2] Accordingly, CD was described as "segmental elephantiasis of the intestine, and sometimes other body parts." This was supported by impressive images of obstructed lymphatic drainage in patients with CD. [1] Van Kruiningen thus dismissed other putative pathogenic factors, such as dysbiosis of the intestinal microbiota and aberrant mucosal immune responses, as being of secondary importance compared to the lymphatic obstruction. We believe, however, that the pathogenesis of $C D$ is considerably 
more complicated, and in this Letter, we return focus to the disturbed intestinal vasculature and microbial function.

It is generally accepted that chronic obliterative lymphangitis does exist in CD. In the late 1960s, Knutson et al. reported a characteristically recurring pattern of obliterative vascular lesions with relative ischaemia of the thickened submucosa in CD lesions. [3] They considered the changes in the vascular system to be of minor pathogenic importance. Twenty years later, however, Wakefield et al. observed several other gastrointestinal vascular changes giving rise to chronic intestinal ischaemia and multifocal gastrointestinal infarction. [4] They concluded it to be a primary process in CD. In previous studies, we assessed mucosal barrier properties in the gut by recovering orally administered polyethylene glycols (PEG) of various molecular sizes in the urine of patients with active CD. [5] We (and others) found low gut uptake of small PEG molecules in CD but a less strict exclusion of the larger PEG molecules. [5, 6] This may be interpreted as a general decrease in the perfusion of the intestinal mucosa as well as increased epithelial permeability of the larger molecules. Unlike exclusive enteral nutrition, treatment with orally administered human immunoglobulin appears to normalise the mucosal barrier function. [7] A hypothesis arising from this is that metabolites from faecal bacteria exert a contractile effect on the mucosal vasculature of the intestine, and that this mechanism is blocked by immunoglobulin treatment.

Moreover, we found convincing evidence of disturbed gut microbial metabolic activity in children and adults with CD. [8,9] In those studies, significant differences in the levels of faecal tryptic activity and faecal bacterial metabolites of cholesterol and bilirubin were seen in patients with active $C D$ compared to healthy individuals, reflecting major disturbances in the intestinal microbial metabolic function. In the adult CD patients, the most striking functional difference was an increased faecal tryptic activity, which was inversely correlated to the levels of Bacteroides in mucosal biopsies and faeces. [9] Collectively, our findings concur well with the prevailing concept of dysbiosis in CD. Furthermore, we found abnormal levels of faecal bacterial metabolites in one of the healthy parents in two of three families with a child with CD, which could indicate that dysbiosis is a genetically or environmentally determined trait predisposing to intestinal inflammation in CD. [8] This is in agreement with recently published findings by Joossens et al. [10] and Torres et al. [11]

Van Kruiningen correctly pointed out that extraintestinal manifestations of $C D$, such as in genitalia, lips or oral cavity, might precede or follow luminal disease. "That CD occurs in these locations, where there is no abscessation, fistulas or microbiome attests to the vascular basis of disease". [1] We, with due respect, disagree with this notion, as active microbes are found at all the locations mentioned. [12] Therefore, dysbiosis should not be neglected in the discussion on the pathogenesis of the disease.

In conclusion, the aetiology of $C D$ is multifactorial and no single pathogenic factor has yet been established. At present, however, intestinal dysbiosis is the most intriguing one of the possible factors, potentially providing us with new targets for treatment. Whatever, our understanding of the disease remains incomplete, and the incidence is rising. [13] We suggest further studies on the pathogenesis of $C D$ to address this issue.

\section{Author Contributions}

All authors contributed equally. 


\section{Competing Interests}

The authors report no conflicts of interest.

\section{References}

1. Van Kruiningen H. Missing the target to treat in Crohn's disease. OBM Hepatol Gastroenterol. 2019; 3: 7. Doi:10.21926/obm.hg.190336.

2. Van Kruiningen HJ, Tonelli P. Elephantiasis and the origins of chronic bowel damage in Crohn's disease. Clin Gastroenterol Hepatol. 2019; 17: 2622-2623. https//doi.org/10.1016/j.ogh.2019.05.008.

3. Knutson H, Lunderquist A, Lunderquist A. Vascular changes in Crohn's disease. Am J Roentgenol. 1968; 103: 380-385.

4. Wakefield AJ, Sawyerr AM, Dhillon AP. Pittillo RM, Rowles PM, Lewis AAM, et al. Pathogenesis of Crohn's disease: Multifocal gastrointestinal infarction. Lancet. 1989; 2: 1057-1062.

5. Magnusson KE, Sundqvist T, Sjödahl R, Tagesson C. Altered intestinal permeability to lowmolecular-weight polyethylene glycols (PEG 400) in patients with Crohn's disease. Acta Chir Scand. 1983; 149: 325-327.

6. Lindberg E, Söderholm JD, Olaison G, Tysk C, Järnerot G. Intestinal permeability to polyethylene glycols in monozygotic twins with Crohn's disease. Scand J Gastroenterol. 1995; 30: 780-783.

7. Sundqvist T, Stenhammar L, Tjellström B, Magnusson KE, Forslund T, Högberg L. Oral immunoglobulin treatment improved intestinal permeability in children with active Crohn's disease. Acta Paediatr. 2017; 106: 647-653.

8. Sundqvist T, Stenhammar L, Tjellström B, Magnusson KE, Midtvedt T, Norin E, et al. Evidence of disturbed gut microbial metabolic activity in pediatric Crohn's disease. J Crohns Colitis. 2019; 1: otz010. Doi:10.1093/crocol/otz010.

9. Midtvedt T, Zabarovsky E, Norin E, Bark J, Gizatullin R, Kashuba V, et al. Increase of faecal tryptic activity relates to changes in the intestinal microbiome: Analysis of Crohn's disease with a multidisciplinary platform. PLoS ONE. 2013; 8: e66074. Doi:10.1371/journal.pone.0066074.

10. Joossens M, Huys G, Cnockaert M, De Preter V, Verbeke K, Rutgeerts $P$, et al. Dysbiosis of the faecal microbiota in patients with Crohn's disease and their unaffected relatives. Gut. 2011; 60: 631-637. Doi:10.1136/gut.2010.223263.

11. Torres J, Hu J, Seki A, Eisele C, Nair N, Huang R, et al. Infants born to mothers with IBD present with altered gut microbiome that transfers abnormalities of the adaptive immune system to germ-free mice. Gut. 2020; 69: 42-51. Doi:10.1136/gutjnl-2018-317855.

12. Martinez-Guryn K, Leone V, Chang EB. Regional diversity of gastrointestinal microbiome. Cell Host Microbe. 2019; 26: 214-224.

13. Malmborg $\mathrm{P}$, Hildebrand $\mathrm{H}$. The emerging global epidemic of paediatric inflammatory bowel disease - causes and consequences. J Internal Med. 2016; 279: 241-58. 


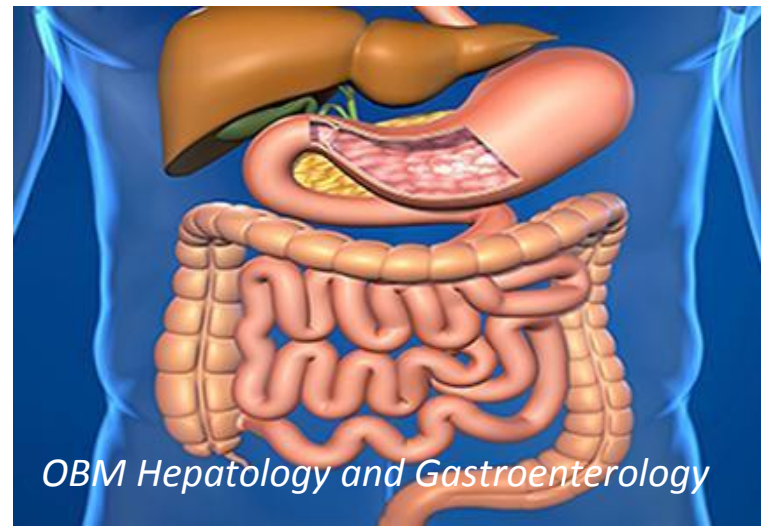

Enjoy $O B M$ Hepatology and Gastroenterology by:

1. Submitting a manuscript

2. Joining in volunteer reviewer bank

3. Joining Editorial Board

4. Guest editing a special issue

For more details, please visit:

http://www.lidsen.com/journals/hg 